\title{
The Role of Mammalian Sirtuins in Cancer Metabolism
}

Carlos Sebastián \& Raul Mostoslavsky

${ }^{1}$ The Massachusetts General Hospital Cancer Center, Harvard Medical School, Boston MA 02114 USA

*Correspondence: rmostoslavsky@mgh.harvard.edu 


\begin{abstract}
Metabolic reprogramming has recently emerged as a key feature of cancer cells, which need to rewire their cellular metabolism in order to sustain their faster proliferation and growth. New insight into the molecular mechanisms governing this metabolic reprogramming has implicated mammalian sirtuins as important regulators of cancer metabolism. Sirtuins are $\mathrm{NAD}^{+}$-dependent protein deacylases involved in a variety of biological functions, including life span and health span regulation, genomic stability, tumorigenesis, inflammation, and metabolism. Due to the requirement of $\mathrm{NAD}^{+}$for their function, sirtuins can act as sensors of the metabolic state of the cell and regulate core metabolic pathways in response to cellular stresses, thus being good candidates to control the reprogramming of cellular metabolism that occurs during tumorigenesis. Here, we summarize our current knowledge of the roles of mammalian sirtuins in cancer metabolism, and discuss their implication in controlling this metabolic shift during aging and aging-associated cancers.
\end{abstract}




\section{Introduction}

One of the key features of cancer cells is their uncontrolled rate of cell division. In order to sustain this increased proliferation, cancer cells need to readjust their cellular metabolism to meet three basic requirements: ATP production to fulfill their energetic demands, biosynthesis of precursors to build up macromolecules, and maintenance of cellular redox status. Indeed, the observation that cancer cells display a different cellular metabolism than normal cells was first described by Otto Warburg more than 50 years ago[1]. In cancer cells, glucose-derived pyruvate is not fully oxidized in the TCA cycle. Instead, it is converted to lactate even in the presence of oxygen, and this metabolic switch is required for cancer cells to proliferate. This finding was interpreted for many years as an adaptive response of cancer cells to their increased proliferation. However, recent work has reset this idea by demonstrating that metabolic reprogramming is a fundamental trait of all cancer cells, one that is directly regulated by oncogenes and tumor suppressors[2, 3]. Moreover, as described in other chapters of this series of reviews, extensive work done in the last decade has extended Warburg's observation to other core cellular metabolic pathways. In a similar way as glucose-derived carbon is shunted to biosynthetic reactions to build up amino acids, lipids and nucleotides, glutamine and serine metabolism are also rewired to provide carbon and nitrogen equivalents to sustain anaplerotic reactions $[4,5]$. Together, all these metabolic changes are essential to fuel cell proliferation and tumor growth and, therefore, cancer metabolism has been recently upgraded to a hallmark of cancer[6].

Several signaling pathways and transcription factors have been identified to regulate the rewiring of central metabolic pathways during tumorigenesis, such as activation of PI3K, stabilization of 
HIF-1, increased expression of MYC, suppression of the metabolic sensor AMPK and loss or mutation of the tumor suppressor p53[2]. Importantly, new insight into the regulation of metabolic reprogramming in cancer cells has implicated the mammalian homologs of the yeast protein Sir2, the so-called sirtuins, as key molecular determinants in controlling cancer metabolism. In mammals, there are 7 sirtuin members (SIRT1-7), which play prominent roles in aging, metabolism, cancer, inflammation, DNA repair and cellular responses to stress[7]. Out of the seven sirtuins, SIRT3, SIRT4 and SIRT6 have been recently shown to directly regulate metabolic reprogramming in cancer cells. Moreover, SIRT1, SIRT2 and SIRT7 could potentially control cancer metabolism by modulating the activity of some important metabolic regulators. In this review, we summarize our current knowledge about the function of this family of proteins in regulating metabolism in the context of tumorigenesis and discuss their putative role in connecting cancer metabolism and aging.

\section{Sirtuins}

The founding member of the sirtuin family, Sir2 (silencing information regulator 2), was originally discovered as a silencing factor in Saccharomyces cerevisiae[8]. Almost two decades later, Sir2 came out as a top candidate in a screen for modulators of yeast life span[9]. Sir2 was found to promote longevity by suppressing the formation of extrachromosomal ribosomal DNA circles in yeast[10]. Soon after these findings, work done by the same laboratory demonstrated that Sir2 was a $\mathrm{NAD}^{+}$-dependent deacetylase required for yeast life span extension upon calorie restriction $(\mathrm{CR})[11,12]$. The discovery of the biochemical activity of Sir2 and its implication in the aging process were the inception of a new field in biology that rapidly expanded: the study of 
Sir2 and its mammalian homologs, the sirtuins. Despite some controversy regarding Sir2 prolongevity effects $[13,14]$, these initial findings prompted many laboratories to characterize the function of the seven mammalian sirtuins, termed SIRT1-7.

All mammalian sirtuins contain a conserved catalytic domain including a large and structurally homologous Rossmann-fold domain for $\mathrm{NAD}^{+}$binding, and a more structurally diverse, smaller, zinc-binding domain[15]. However, their N- and C-termini differ in sequence and length, which might explain their different subcellular localization, targets and functions[7] (Figure 1; Table1). SIRT1 and SIRT2 are found in the cytoplasm and in the nucleus, SIRT3-5 are mitochondrial sirtuins while SIRT6 and SIRT7 are mainly found in the nucleus[16]. Biochemically, mammalian sirtuins are primarily $\mathrm{NAD}^{+}$-dependent lysine deacetylases. However, some recent data has demonstrated that some sirtuins have evolved to remove other acyl groups, such as succinyl, malonyl, glutaryl and long chain fatty acyl groups[17-21]. Moreover, SIRT4 and SIRT6 possess ADP-ribosyltransferase activity, yet its biological relevance remains to be fully established [22-25]. Together, all these enzymatic activities are essential for mammalian sirtuins to modulate a variety of physiological processes, such as transcriptional regulation, genomic stability, cellular responses to stress, metabolism, inflammation, aging and cancer[7] (Figure 1).

Mouse models to study the function of mammalian sirtuins have been recently generated. From the analysis of their genotype, one can immediately infer that this family of proteins has prominent roles in regulating metabolism. Due to their $\mathrm{NAD}^{+}$dependency, sirtuin activity is tightly linked to the metabolic state of the cell; thus, it has been proposed that sirtuins can act as metabolic sensors coordinating cellular responses to metabolic stresses. Indeed, nearly every 
sirtuin plays a role in regulating metabolism and energy homeostasis by controlling multiple metabolic pathways, such as lipid and glucose metabolism, ketone bodies synthesis, urea cycle and insulin secretion[7, 26]. Furthermore, sirtuins appear to be key players in the beneficial effects of $\mathrm{CR}$ on healthy life span extension. CR promotes the expression of nicotinamide phosphoribosyltransferase (NAMPT), a rate-limiting enzyme of $\mathrm{NAD}^{+}$biosynthesis, leading to an increase in intracellular levels of $\mathrm{NAD}^{+}$, and concomitantly, to the activation of sirtuin activity[11, 27]. Importantly, SIRT1 and SIRT3 improve healthy aging in mice by protecting against several age-related pathologies[28-30], and brain-specific SIRT1- and whole body SIRT6-overexpressing mice exhibit extended life span[31, 32], highlighting the importance of sirtuins in mammalian healthy life span and aging.

Aging is one of the most potent factors contributing to cancer, whose incidence increases exponentially with age[33]. Due to their role in regulating longevity and age-related pathologies, sirtuins represent good candidates to control tumorigenesis as well. Indeed, almost every sirtuin has been implicated in neoplastic transformation with both tumor suppressive and promoting functions depending on the specific tumor type, cellular context and signaling pathway affected[7, 34]. Initially, most of the studies involving sirtuins in cancer focused on their ability to control cellular stress responses and DNA repair. However, as detailed below, a large body of evidence has recently shown that sirtuins have a prominent role in tumorigenesis by regulating energy metabolism in cancer cells[35-39]. Thus, it appears that this family of proteins could be at the crossroad of metabolism, cancer and aging.

\section{Mitochondrial sirtuins: controlling tumor growth from the powerhouse}


SIRT3 acts as a tumor suppressor by inhibiting glycolysis

As mentioned before, SIRT3, SIRT4 and SIRT5 reside in the mitochondria, where they control numerous aspects of mitochondrial metabolism. SIRT3 is the most studied and best characterized among mitochondrial sirtuins. It has a very robust deacetylase activity and represents the major regulator of the mitochondrial acetylome. SIRT3 KO mice and cells exhibit increased mitochondrial protein acetylation[40, 41], and SIRT3 has been shown to control the acetylation of a vast number of mitochondrial proteins in response to $\mathrm{CR}$ and fasting[42, 43]. By deacetylating and controlling the activity of its targets, SIRT3 regulates multiple metabolic pathways, some of which could have profound consequences for tumor growth[26]. Indeed, SIRT3 has been found to be a tumor suppressor, mainly by inhibiting mitochondrial ROS production through deacetylation and activation of SOD2, IDH2 and FoxO3a[29, 37, 44-47]. Loss of SIRT3 leads to an increase in ROS levels, which via stabilization of HIF1 $\alpha$, drives a metabolic reprogramming towards aerobic glycolysis promoting tumor growth[37, 44]. Furthermore, SIRT3 regulates glycolytic metabolism by deacetylating and activating pyruvate dehydrogenase (PDH)-E1 $\alpha[48,49] \square \square \mathrm{PDH}$ is a key glycolytic enzyme that converts pyruvate into acetyl-CoA, which will be further oxidized in the TCA. Reduced PDH activity is a feature of cancer cells, mainly due to overexpression of pyruvate dehydrogenase kinases (PDK), which phosphorylate and inactivate PDH. SIRT3 deacetylates PDH- E1 $\alpha$ at lysine 321 increasing its activity, and thus promoting pyruvate oxidation in the mitochondria. Lack of SIRT3 or expression of a mutant PDH- E1 $\alpha$ mimicking a constitutively acetylated lysine 321 (K321Q) decrease PDH activity and promote aerobic glycolysis, increasing the tumorigenic potential of 
cancer cells[48]. Finally, SIRT3 has been recently described as a critical regulator of pancreatic tumor growth by controlling the malate-aspartate NADH shuttle activity[50]. This shuttle is important to transfer NADH from the cytosol into the mitochondria to sustain a high rate of glycolysis in tumor cells. SIRT3 deacetylates mitochondrial glutamate oxaloacetate transaminase (GOT2), a key enzyme controlling the malate-aspartate NADH shuttle, at lysines 159, 185 and 404. Increased GOT2 acetylation in absence of SIRT3 promotes the net transfer of cytosolic $\mathrm{NADH}$ into the mitochondria, supporting ATP production and cancer cell proliferation. Importantly, GOT2 K159 acetylation is increased in human pancreatic tumors, which correlates with reduced SIRT3 expression[50]. Moreover, SIRT3 expression is also downregulated in breast cancer, colon carcinoma, osteosarcoma, and hepatocellular carcinoma, and SIRT3 KO mice develop spontaneous mammary tumors, further supporting a tumor-suppressor role for this protein[37, 44, 45, 51, 52].

Despite not having been directly assessed, other SIRT3-regulated metabolic pathways could potentially have a role in metabolic rewiring during tumorigenesis. SIRT3 has a prominent role in promoting an efficient electron transport chain (ETC) function by deacetylating several components of the ETC complex I (such as NDUFA9), complex II (SDHA) and complex V (ATP synthase subunit $\beta$ )[53-55]. In this way, SIRT3 maintains cellular ATP levels by promoting oxidative phosphorylation, thus avoiding potential activation of a Warburg-like metabolism. Moreover, keeping an efficient ETC reduces the levels of reactive oxygen species (ROS), which, as noted before, are important regulators of the Warburg effect. On the other hand, SIRT3 regulates acetate metabolism by deacetylating and activating acetyl-CoA synthetase 2 (ACSS2)[56, 57]. ACSS2 catalyzes the conversion of acetate into acetyl-CoA and, as recently 
reported, it is overexpressed in cancer cells to produce enough acetyl-CoA to build up lipid biomass to fuel cell proliferation, in particular under hypoxic conditions[58-60]. In this context, it could be possible that SIRT3 could act as an oncogene to promote acetate utilization in cancer cells through activation of ACSS2. Indeed, it has been described that SIRT3 has some tumor promoting roles in specific types of cancer[61-63]. Overall, despite being described as a tumor suppressor, it is likely that SIRT3 may act as a tumor suppressor or an oncogene, in a tissue and context-specific manner.

SIRT4 limits tumor growth via repression of glutamine metabolism

Recent studies have shown that SIRT4 has important roles in cell metabolism and carcinogenesis as well. Despite having a conserved deacetylase domain, SIRT4 was initially described to have robust ADP-ribosyltransferase activity[22, 24]. The mitochondrial enzyme glutamate dehydrogenase (GDH) was the first substrate of SIRT4 to be identified[24]. GDH is a key enzyme in glutamine metabolism and catalyzes the conversion of glutamate into $\alpha$-ketoglutarate. SIRT4 ADP-ribosylates GDH to repress its activity resulting in a blockade of glutamine metabolism and a suppression of amino-acid-stimulated insulin secretion in pancreatic $\beta$ cells[24]. Recent data has demonstrated that SIRT4 also possesses a biologically relevant deacetylase activity. SIRT4 deacetylates and inhibits malonyl-CoA decarboxylase, the enzyme responsible for the generation of acetyl-CoA from malonyl-CoA, thus controlling fatty acid oxidation[64]. Moreover, SIRT4 also suppresses fatty acid oxidation by modulating the activity of PPAR $\alpha$ and AMPK[65, 66]. Finally, a new enzymatic activity has been recently associated with this mitochondrial sirtuin. SIRT4 can hydrolyze lipoamide groups from proteins, acting as a 
cellular lipoamidase[67]. In particular, SIRT4 removes lipoamide cofactors from the E2 component dihydrolipoyllysine acetyltransferase (DLAT) of PDH, diminishing its activity[67].

As observed for SIRT3, SIRT4 expression is downregulated in a variety of human tumors, including breast, colon, bladder, gastric, ovarian, thyroid and lung cancers, supporting a role for this sirtuin as a tumor suppressor[35, 68-70]. In line with this, SIRT4 KO mice display increased incidence of solid tumors, especially lung tumors[35]. Mechanistically, SIRT4 suppresses tumorigenesis by inhibiting glutamine metabolism and promoting genomic stability[35, 36, 71]. As mentioned before, cancer cells avidly uptake glutamine to use it as an anaplerotic substrate to feed the TCA cycle. Glutamine-derived $\alpha$-ketoglutarate is used to replenish the TCA cycle to support the biosynthesis of other amino acids and fatty acids. Moreover, in tumor cells with defective mitochondria or under hypoxia, the TCA cycle is inhibited, yet glutamine can still contribute to lipid biosynthesis by reductive carboxylation of $\alpha$-ketoglutarate into citrate through a reverse enzymatic reaction of isocitrate dehydrogenase (IDH)[72, 73]. Therefore, by inhibiting the activity of GDH, SIRT4 controls this key step in glutamine metabolism reprogramming in cancer cells, in turn promoting tumor growth. In this line of evidence, it has been shown that DNA damaging agents induce the expression of SIRT4 to repress glutamine metabolism and halt cell proliferation, allowing the cell to repair the damage. Accordingly, loss of SIRT4 results in increased glutamine-dependent proliferation and stress-induced genomic instability, promoting tumor growth[35]. SIRT4-dependent inhibition of glutamine metabolism has been also reported to suppress MYC-driven human Burkitt lymphoma[71]. Due to the aberrant activation of the transcription factor MYC, which regulates glutamine metabolism[74, 75], Burkitt lymphoma cells exhibit increased glutamine uptake and metabolism. Overexpression of SIRT4 in these cells 
reduces glutamine utilization and glutamine-dependent proliferation, and sensitizes them to glucose depletion. Moreover, SIRT4 deletion in a mouse model of Burkitt lymphoma increases tumorigenesis and mortality by increasing glutamine metabolism[71]. Finally, mTORC1 activation, which has been linked to glutamine addiction in cancer cells[76], represses SIRT4 expression by promoting proteasome-mediated degradation of cAMP-responsive element binding 2 (CREB2), a SIRT4 transcriptional regulator[36]. Similarly, C-terminal-binding protein $(\mathrm{CtBP})$, a transcription factor controlling tumor initiation, progression and metastasis, has been found to have an essential role in promoting glutaminolysis by directly repressing the expression of SIRT4 in cancer cells[77].

SIRT4 could also act as an oncogene by promoting glucose metabolic reprogramming in cancer cells via inhibition of PDH. As noted before, SIRT4 functions as a lipoamidase to diminish PDH activity, a feature of cells experiencing Warburg effect. However, overexpression or increased activity of SIRT4 in tumors has not been documented to date. Therefore, further experiments are needed to confirm this hypothesis and determine the functional role of SIRT4 ADPribosyltransferase and lipoamidase activities in the context of tumorigenesis.

\section{SIRT5 and cancer}

Although initially considered a deacetylase based on its homology to other sirtuins[78], more recent work has demonstrated that SIRT5 functions primarily as a malonyl, succinyl and glutaryl deacylase[17, 20, 21, 42, 79]. As SIRT3 might be considered a regulator of the mitochondrial acetylome, SIRT5 has emerged as the sirtuin controlling the mitochondrial succinylome and 
glutarylome due to the large amount of substrates with significant increase in these posttranslational modifications found in SIRT5 KO mice and tissues. Among them, several proteins implicated in diverse metabolic pathways have been identified. SIRT5 regulates the urea cycle by deacetylating, desuccinylating and deglutarylating carbamoyl phosphate synthetase 1 (CPS1), in turn increasing its activity[17, 21, 80, 81]. CPS1 catalyzes the first step of the urea cycle for ammonia detoxification in the liver and, to a lesser extent, in the kidney. Importantly, SIRT5 has also been reported to regulate ammonia production and ammonia-induced autophagy in non-liver cells by regulating glutamine metabolism. Mechanistically, SIRT5 desuccinylates and inhibits glutaminase, the enzyme catalyzing the conversion of glutamine into glutamate in a reaction producing ammonia[82]. Furthermore, SIRT5 plays an important role in ROS detoxification, as it desuccinylates and activates $\mathrm{Cu} / \mathrm{Zn}$ superoxide dismutase (SOD1)[83], a key antioxidant enzyme. SIRT5 also controls glucose oxidation by repressing the activity of PDH-E1 $\alpha$ and succinate dehydrogenase (SDH) by directly desuccinylating these enzymes[79]. Importantly, SOD1, PDH- E1 $\alpha$ and SDH have been implicated in tumorigenesis. SOD1 expression has been found to be upregulated in breast cancer cell lines[84], and its overexpression correlates with increased growth of lung cancer cells[85, 86]. Interestingly, mutation of the SOD1 succinylation site inhibits the growth of lung cancer cells, suggesting that SIRT5 could promote tumor growth by desuccinylating and activating SOD1[83]. As noted before, suppression of PDH activity is important for cancer cells to reprogram their glucose metabolism. Moreover, inactivating mutations in SDH have been associated with tumorigenesis by stabilizing HIF-1 $\alpha$ [87].Therefore, SIRT5 could potentially act as an oncogene by inactivating these enzymes, thus promoting glucose metabolic reprogramming and tumor growth. $\square$ In line with this, the genomic region comprising the SIRT5 locus has been recently found to be amplified in $30 \%$ of human high-grade 
serous ovarian carcinomas, and SIRT5 is overexpressed in advanced non-small cell lung carcinoma[88, 89].

\section{SIRT6: bridging chromatin and cancer metabolism}

SIRT6 is almost exclusively localized to chromatin, where it functions primarily as a histone deacetylase by removing acetyl groups from lysines 9 and 56 of histone H3[90-92]. However, it has been reported that in vitro SIRT6 deacetylase activity is very weak, being about 1000 fold lower than SIRT1 deacetylase activity[18, 19]. This discrepancy between SIRT6 in vivo and in vitro enzymatic activity has been in part attributed to the fact that SIRT6 requires to be in a full nucleosome context (rather that purified histones) to be fully active[93], and recent work demonstrated that SIRT6 deacetylase activity is highly increased by free fatty acids (which were not present in the initial in vitro studies)[18]. In addition to its deacetylase activity, SIRT6 also exhibits deacylase and ADP-ribosyltransferase activities. SIRT6 removes long-chain fatty acyl groups (myristoyl and palmitoyl) from lysine residues in vitro[18], and demyristoylates TNF $\alpha$ at lysines 19 and 20 allowing TNF $\alpha$ to be secreted by macrophages[19]. Although very weak, SIRT6 ADP-ribosyltransferase activity appears to be biologically relevant in the context of DNA damage upon oxidative stress, since SIRT6 ADP-risbosylates poly-ADP-ribose-polymerase (PARP1) stimulating its activity, thus promoting DNA repair[94]. Moreover, SIRT6-dependent ADP-ribosylation of the nuclear corepressor protein KAP1 contributes to the packaging of retrotransposons into transcriptionally repressive heterochromatin promoting genomic stability[95]. 
Through all its enzymatic activities, SIRT6 controls cellular homeostasis by regulating DNA repair[94, 96-99], telomere maintenance[90], and glucose and lipid metabolism[100-104]. Importantly, the main phenotype that SIRT6 KO mice display is an acute and severe metabolic abnormality. Soon after birth, they develop a striking phenotype characterized by several acute degenerative processes, including loss of subcutaneous fat, lymphopenia, osteopenia, and acute onset of hypoglycemia, which lead to their death in less than 10 days[96]. This fatal drop in blood glucose levels is due to an increased glucose uptake by both muscle and brown adipose tissue. SIRT6-deficient cells avidly take up glucose, which is metabolized to lactate instead of being oxidized in the mitochondria[102]. Mechanistically, SIRT6 binds and co-represses HIF$1 \alpha$ transcriptional activity, thus suppressing the expression of several key glycolytic genes, such as glucose transporter-1 (Glut1), phosphofructokinase-1 (Pfk1), pyruvate dehydrogenase kinase$1(P d k l)$ and lactate dehydrogenase $(L d h)$ by specifically deacetylating $\mathrm{H} 3 \mathrm{~K} 9$ at the promoter region of these genes[102]. Accordingly, lack of SIRT6 leads to a glucose metabolic reprogramming that is reminiscent of the Warburg effect, suggesting that this sirtuin could suppress tumor growth. Indeed, SIRT6 functions as a tumor suppressor by repressing cancer metabolism. SIRT6 loss in immortalized mouse embryonic friboblasts (MEFs) leads to tumor formation even in the absence of any oncogene activation[38]. Metabolic reprogramming has been traditionally associated with the activation of oncogenic pathways, which, in addition to their effects on cell proliferation, directly impinge on core metabolic pathways. However, given the connection between these two processes, it has been difficult to discern cause from effect. In this context, these results represent one of the first evidence supporting a driving role for glucose metabolism reprogramming in tumorigenesis[105]. Importantly, inhibition of glucose metabolism by knocking-down PDK1 suppresses tumorigenesis in SIRT6-deficient cells, 
confirming the driver role of glycolytic metabolism in cancer initiation and growth[38]. In addition to promoting glycolysis, lack of SIRT6 leads to an increase in glutamine metabolism and ribosomal gene expression, although this phenotype appears to be a later event in the tumorigenic process. SIRT6 deacetylates H3K56 at the promoter region of these genes and co-

represses MYC transcriptional activity, a master regulator of glutamine metabolism and ribosome biogenesis[38]. Furthermore, SIRT6 deletion in a mouse model of colorectal cancer increases the number, size and aggressiveness of adenomas, a phenotype that is fully suppressed by pharmacologically inhibiting PDK1 with dichloroacetate (DCA), highlighting the prominent role of glycolysis in SIRT6-dependent tumorigenesis[38]. Finally, SIRT6 expression is downregulated in human pancreatic, colorectal, liver and head and neck cancers[38, 106-108]. Several mechanisms have been proposed to regulate SIRT6 levels in cancer cells, including proteasomal degradation in colon cancer cells and non-small cell lung cancer[109, 110], and direct repression of its expression in breast, bladder and prostate cancer cells[111, 112].

Like other sirtuins, increased SIRT6 expression has also been reported in few tumor types, such as pancreatic, prostate and breast cancers, where high SIRT6 levels are associated with chemotherapy resistance and poor prognosis[113-115]. In these tumors, the effect of SIRT6 on metabolism may not be dominant, but instead overexpression of SIRT6 may promote a proinflammatory phenotype or offer protection against chemotherapy-induced DNA damage, facilitating tumor growth.

\section{SIRT1, SIRT2 and SIRT7: putative regulators of tumor metabolism}


A large body of evidence has implicated SIRT1, SIRT2 and SIRT7 in neoplastic transformation. Although they have not been found to directly regulate cancer metabolism, recent data has uncovered new roles for these sirtuins in the regulation of key factors controlling metabolic reprogramming in cancer cells. As detailed below, SIRT1, SIRT2 and SIRT7 regulate the activity of both HIF and MYC proteins; SIRT1 also regulates the metabolic sensor liver kinase B1 (LKB1), and SIRT2 regulates de activity of several metabolic enzymes. Therefore, it is reasonable to speculate that these sirtuins could play important roles in tumorigenesis by regulating some aspects of tumor metabolism, a possibility that has not been fully explored yet.

SIRT1 was the first family member shown to function as a tumor suppressor, mainly by modulating cellular stress responses and DNA repair[116]. However, SIRT1 has also been found to promote tumor growth; therefore, like for other sirtuins, the role of SIRT1 in tumorigenesis seems to depend on the specific tumor type, cellular context and signaling pathway affected. SIRT1 possesses a very strong deacetylase activity and, accordingly, it regulates tumorigenesis by deacetylating and controlling the activity of a large variety of transcription factors, some of them key regulators of metabolic reprogramming in cancer cells. It was initially reported that SIRT1 was able to deacetylate and activate HIF-2 $\alpha$ but not HIF-1 $\alpha$ [117], although later studies confirmed a role for SIRT1 in regulating HIF-1 $\alpha$ as well[118, 119]. SIRT1 was found to deacetylate HIF-1 $\alpha$ inhibiting its transcriptional activity by blocking HIF-1 $\alpha$-dependent recruitment of the p300 acetyltransferase to the promoters of HIF-1 $1 \alpha$ target genes. In this setting, SIRT1 could repress HIF-1 $\alpha$-driven metabolic reprogramming[118]. However, these results have been challenged by another study, which showed a positive effect of SIRT1 on HIF-1 $\alpha$ activity[119]. This study demonstrated that in vivo inhibition of SIRT1 activity in mice bearing 
hepatocellular carcinoma xenografts reduces tumor growth by downregulating the expression of VEGFA and blood vessel formation. In line with this, lack of SIRT1 in myeloid-derived suppressor cells (MDSC) promotes a HIF-1 $\alpha$-dependent glycolytic switch that skews these cells towards a pro-inflammatory phenotype, which confer protection against tumors[120]. Finally, SIRT1 can have differential roles in HIF- $1 \alpha$ and HIF- $2 \alpha$ mediated hypoxic responses depending on the cell type[121], adding more complexity to the functional interplay between SIRT1 and HIF proteins.

In addition to HIF, SIRT1 also cooperates with the oncogenic transcription factor MYC. MYC directly binds to the SIRT1 promoter to induce its expression, which in turn deacetylates MYC at its C-terminal domain[122-124]. Although initially reported that SIRT1-mediated deacetylation of MYC was responsible for its degradation and, consequently, decreased MYC function[123], more recent studies have demonstrated that MYC deacetylation leads to its stabilization and increases MYC-MAX association and activity[122, 124]. In this context, SIRT1 also forms a positive feedback loop with $\mathrm{N}-\mathrm{Myc}$ to promote tumorigenesis in a mouse model of neuroblastoma, where N-Myc induces the expression of SIRT1, and SIRT1 stabilizes N-Myc protein by promoting MKP3-dependent phosphorylation of N-Myc[125]. Despite all these data supporting a role for SIRT1 in regulating MYC activity, it is currently unknown whether SIRT1 regulates MYC-dependent metabolic reprogramming in cancer cells. In this regard, it has been recently shown that SIRT1 stimulates MYC-induced LDHA expression[122, 126], suggesting that, indeed, SIRT1 could regulate some of the metabolic effects of MYC in cancer. 
Finally, it has been reported that SIRT1 deacetylates and activates LKB1[127], a known tumor suppressor that regulates several metabolic pathways. One of the main targets for LKB1 is AMPactivated protein kinase (AMPK), a key enzyme that regulates cellular energy homeostasis[128]. LKB1 phosphorylates AMPK at Thr-172, an event required for its activation[129]. Importantly, AMPK has been recently described to be a tumor suppressor by negatively regulating the Warburg effect[130], raising the possibility that SIRT1 could suppress metabolic reprogramming in cancer cells by activating the LKB1-AMPK axis.

SIRT2 also functions as a tumor suppressor, mainly by promoting genomic stability. SIRT2 regulates mitotic progression by controlling the activity of the anaphase promoting complex/cyclosome via deacetylation of its coactivators $\mathrm{CDH} 1$ and $\mathrm{CDC} 20$, and thus prevents chromosomal instability during mitosis[131]. Furthermore, SIRT2 binds and deacetylates the methyltransferase PR-Set7, modulating its chromatin localization and resulting in H4K20 methylation, a chromatin mark involved in genomic stability[132]. Interestingly, CDH1 has been shown to inhibit glycolysis and cancer cell proliferation through ubiquitination and degradation of the glycolytic enzyme 6-phosphofructo-2-kinase/fructose-2,6-bisphosphatase, isoform 3 (PFKFB3)[133], suggesting that SIRT2-mediated deacetylation of CDH1 could regulate aerobic glycolysis. Supporting this hypothesis, SIRT2 has been recently found to regulate the activity of HIF-1 $\alpha$ by deacetylating lysine 709 and promoting its stability. Importantly, HIF-1 $\alpha$ induction by SIRT2 deficiency increases the expression of the glycolytic genes GLUT1 and LDHA, supporting tumor growth[134]. Furthermore, SIRT2 also regulates the activity of phosphoglycerate mutase (PGAM) and glucose-6-phosphate dehydrogenase (G6PD), two key metabolic enzymes involved in glycolysis and the pentose phosphate pathway (PPP). PGAM is a 
glycolytic enzyme that catalyzes the conversion of 3-phosphoglycerate (3-PG) to 2phosphoglycerate (2-PG). By controlling intracellular levels of 3-PG and 2-PG, PGAM coordinates glycolysis and biosynthesis to promote tumor growth[135]. Xu and colleagues found that PGAM activity is regulated by acetylation at lysine 100, and SIRT2 deacetylates this residue to activate its enzymatic activity[136]. Although SIRT2-dependent deacetylation of PGAM was not confirmed to be relevant for tumor growth in vivo, overexpression of a PGAM acetylation mimetic mutant reduced cell proliferation and tumor growth[136], highlighting the importance of this acetylation in controlling PGAM activity in the context of tumorigenesis. As noted before, SIRT2 also deacetylates G6PD, which catalyzes the conversion of glucose-6-phosphate to 6phosphogluconate generating NADPH, and represents the rate-limiting and primary control step of the NADPH-generating branch in the PPP. SIRT2-mediated deacetylation of G6PD activates its enzymatic activity and stimulates PPP to supply cytosolic NADPH promoting cell survival during oxidative stress[137]. Since an active PPP is important in tumor cells for nucleotide biosynthesis and redox homeostasis, this result imply that SIRT2 could potentially promote tumor growth by activating this metabolic pathway.

As for SIRT1, the MYC oncoproteins also form a positive feedback loop with SIRT2. Both MYC and N-MYC induce the expression of SIRT2, which in turn deacetylates and stabilizes them, promoting growth of neuroblastoma and pancreatic cancer cells[138]. However, whether the interplay between SIRT2 and MYC proteins is relevant in the context of cancer metabolism remains unexplored. 
Lastly, although the role of SIRT7 in tumorigenesis has been less studied, a recent report showed pro-oncogenic properties for this sirtuin by deacetylating $\mathrm{H} 3 \mathrm{~K} 18$ and repressing transcription of multiple genes involved in anchorage-independent growth and contact inhibition[139]. In line with this, SIRT7 has been also described to act as an oncogene in hepatocellular carcinoma, gastric cancer and colorectal cancer[140-142]. As other sirtuins, SIRT7 also regulates HIF proteins, potentially underlying the Warburg effect. SIRT7 binds and decreases the stability of both HIF-1 $\alpha$ and HIF-2 $\alpha$, although the molecular mechanism involved in this regulation is not known[143]. Finally, SIRT7 also acts as a co-repressor of MYC to suppress ribosomal gene expression in response to endoplasmic reticulum (ER) stress[144]. Nevertheless, whether SIRT7 plays a role in cancer-associated metabolic reprogramming remains to be elucidated.

\section{Sirtuins as modulators of cancer metabolism during aging}

Medical advances and global heath policies have resulted in an increase in life expectancy. This shift in the distribution of population towards older ages has profound medical implications. Aging is accompanied with a major incidence of many diseases, and roughly two thirds of people who die each day in the world die of age-related causes (this percentage reaches $90 \%$ in industrialized countries)[145]. Remarkably, cancer ranks at the top of the list of age-related deaths and its incidence increases exponentially with age[33]. The most common explanation for the higher incidence of cancer during aging is the accumulation of mutations over time as we age, providing aging enough time for these mutations to reach the threshold required for tumor initiation and growth. However, this theory has some caveats as it fails to explain why some

metabolic diseases, such as type II diabetes or obesity, exhibit a tight correlation with cancer 
propensity and worse prognosis[146]. In line with this, metabolic alterations via CR or physical exercise drastically reduce the risk of developing cancer[147]. These observations suggest that a decrease in metabolic homeostasis as we age could be an important factor contributing to the increased incidence of cancer during aging. In this setting, metabolism in tissues is known to change with age, with a clear decrease in mitochondrial respiration coupled to an increased in lactate metabolism[148, 149]. Moreover, some tissues exhibit increased aerobic glycolysis with age, mainly due to upregulated activities of several glycolytic enzymes[150-152]. These metabolic changes are remarkably similar to cancer metabolism reprogramming, raising the possibility that age-associated changes in metabolism could predispose to tumorigenesis and promote tumor growth.

Increased ROS production, p53 and NF- $\mathrm{BB}$ have been involved in this age-dependent metabolic switch[153]. However, the precise molecular players directly regulating this adaptation remain poorly understood. As mentioned before, sirtuins have emerged as key regulators of metabolic rewiring during tumorigenesis, and they play a crucial role in regulating healthy lifespan and aging. Therefore, they represent excellent candidates to connect cancer, aging and metabolic reprogramming. Although there is no data directly linking sirtuins as regulators of age-associated cancers by controlling metabolism, several lines of evidence support this hypothesis. The levels of $\mathrm{NAD}^{+}$decrease in multiple tissues during aging, mainly due to a downregulation of nicotinamide phosphoribosyltransferase (NAMPT), the rate-limiting enzyme in mammalian $\mathrm{NAD}^{+}$biosynthesis[154]. Since sirtuins require $\mathrm{NAD}^{+}$for their activity, this result suggests that the function of these proteins could be impaired during aging. Importantly, nicotinamide mononucleotide $(\mathrm{NMN})$, a product of the NAMPT reaction and a key $\mathrm{NAD}^{+}$intermediate, 
ameliorates the metabolic defects associated with decreased $\mathrm{NAD}^{+}$during aging, partly through SIRT1 activation[154]. In agreement with this, SIRT1 overexpression in mice improves healthy aging, while decreasing the incidence of spontaneous carcinomas and sarcomas. These effects, however, are not sufficiently potent to affect longevity, but clearly suggest a protective role for SIRT1 in age-associated cancers[28]. Furthermore, CR induces the expression of SIRT1 in several tissues[155], and overexpression or pharmacological activation of SIRT1 mimics the protective effects of $\mathrm{CR}$ on age-associated metabolic decline, neurodegeneration and cancer [156]. Remarkably, SIRT1 has been recently involved in the establishment of a Warburg-like phenotype during aging by stabilizing HIF-1 $\alpha$ and disrupting mitochondrial homeostasis[157]. Drop of $\mathrm{NAD}^{+}$levels occurs during aging, in turn decreasing SIRT1 activity, causing VHL levels to decline promoting the stabilization of HIF-1 $\alpha$. The activation of this program induces a pseudohypoxic state that disrupts nuclear-mitochondrial communication and OXPHOS, which could promote tumorigenesis by increasing ROS levels and mutagenesis[157]. Importantly, a decline in mitochondrial function with age has been linked to loss of cellular homeostasis and organismal health[158]. Besides SIRT1, mitochondrial sirtuins also regulate mitochondrial metabolism as well as some aspects of cancer metabolism and, thus, they could also control ageassociated cancers by impacting on mitochondrial homeostasis. Furthermore, SIRT3 and SIRT6 also regulate HIF-1 $\alpha$ activity, raising the possibility that these sirtuins could contribute as well to the acquisition of this pseudohypoxic state during aging. Finally, SIRT6 overexpression extends lifespan in male mice[32], a phenotype that has been partially attributed to its role as a tumor suppressor[159]. Due to the driving role of SIRT6 in tumorigenesis by controlling glucose metabolic reprogramming[38], it is tempting to speculate that loss of SIRT6 (levels or activity) 
could contribute to the Warburg-like metabolic shift observed during aging, promoting tumorigenesis.

\section{Concluding remarks}

Extensive work done over the past few years has greatly improved our understanding of the biology behind mammalian sirtuins, which have been involved in a steadily growing list of physiological processes. Due to their $\mathrm{NAD}^{+}$-dependent activity, sirtuins function as cellular rheostats controlling core metabolic pathways and, thus, are essential in maintaining metabolic homeostasis. Changes in carbon and nitrogen metabolism have been shown to be strictly required for tumor initiation and progression and, accordingly, cancer cells need to reprogram their metabolism to fulfill the energetic and anabolic demands of cell proliferation. Not surprisingly, as metabolic sensors, several sirtuins have been uncovered as central regulators of this metabolic reprogramming by modulating mitochondrial metabolism (SIRT3 and SIRT4) and epigenetics (SIRT6). Although the role of other sirtuins in driving cancer metabolism has not been explored yet, they clearly regulate some of the metabolic pathways altered in cancer and, with no doubt, future work will likely involve these sirtuins in tumorigenesis by controlling metabolism in cancer cells. However, further work seems necessary to understand how sirtuins' expression/activity is regulated during tumorigenesis, and whether their roles in cancer metabolism are general or specific for some types of tumors. Moreover, almost every sirtuin has other relevant functions in cancer cells, from promoting DNA repair to controlling the activity of transcription factors, and depending on the dominant role of some of these activities, sirtuins will have tumor promoting or suppressing roles. Therefore, elucidating the precise interplay of these 
functions in a particular tumor will be essential to design drugs to efficiently target this family of proteins. In this regard, controlling the activity of sirtuins could have an enormous impact on age-related diseases, including cancer. As discussed before, the role of sirtuins as regulators of cancer metabolism could be one of the mechanisms by which they promote longevity and health span, defining this family of proteins as key modulators at the intersection of cancer, metabolism and aging. 


\section{ACKNOWLEDGEMENTS}

Work in the Mostoslavsky's lab is supported in part by NIH grants 1R01CA175727-01A1, R21CA185416-01, and 1R21ES025638-01. R.M. is the Kristine and Bob Higgins MGH Research Scholar, the Warshaw Institute Fellow, and a Howard Goodman Awardee. C.S. is the recipient of a Visionary Postdoctoral Award from the Department of Defense.

\section{REFERENCES}

[1] Warburg O. On the origin of cancer cells. Science 1956;123:309-14.

[2] Cairns RA, Harris IS, Mak TW. Regulation of cancer cell metabolism. Nat Rev Cancer 2011;11:85-95.

[3] Lunt SY, Vander Heiden MG. Aerobic glycolysis: meeting the metabolic requirements of cell proliferation. Annu Rev Cell Dev Biol;27:441-64.

[4] Hensley CT, Wasti AT, DeBerardinis RJ. Glutamine and cancer: cell biology, physiology, and clinical opportunities. J Clin Invest 2013;123:3678-84.

[5] Locasale JW. Serine, glycine and one-carbon units: cancer metabolism in full circle. Nat Rev Cancer 2013;13:572-83.

[6] Hanahan D, Weinberg RA. Hallmarks of cancer: the next generation. Cell 2011;144:64674. 
[7] Sebastian C, Satterstrom FK, Haigis MC, Mostoslavsky R. From sirtuin biology to human diseases: an update. J Biol Chem 2012;287:42444-52.

[8] Klar AJ, Strathern JN, Broach JR, Hicks JB. Regulation of transcription in expressed and unexpressed mating type cassettes of yeast. Nature 1981;289:239-44.

[9] Kaeberlein M, McVey M, Guarente L. The SIR2/3/4 complex and SIR2 alone promote longevity in Saccharomyces cerevisiae by two different mechanisms. Genes Dev 1999;13:2570-80.

[10] Sinclair DA, Guarente L. Extrachromosomal rDNA circles--a cause of aging in yeast. Cell 1997;91:1033-42.

[11] Imai S, Armstrong CM, Kaeberlein M, Guarente L. Transcriptional silencing and longevity protein Sir2 is an NAD- dependent histone deacetylase. Nature 2000;403:795-800.

[12] Lin SJ, Defossez PA, Guarente L. Requirement of NAD and SIR2 for life-span extension by calorie restriction in Saccharomyces cerevisiae. Science 2000;289:2126-8.

[13] Burnett C, Valentini S, Cabreiro F, Goss M, Somogyvari M, Piper MD, et al. Absence of effects of Sir2 overexpression on lifespan in C. elegans and Drosophila. Nature 2011;477:482-5.

[14] Longo VD, Kennedy BK. Sirtuins in aging and age-related disease. Cell 2006;126:25768.

[15] Feldman JL, Dittenhafer-Reed KE, Denu JM. Sirtuin catalysis and regulation. J Biol Chem 2012;287:42419-27.

[16] Michishita E, Park JY, Burneskis JM, Barrett JC, Horikawa I. Evolutionarily Conserved and Nonconserved Cellular Localizations and Functions of Human SIRT Proteins. Mol Biol Cell 2005. 
[17] Du J, Zhou Y, Su X, Yu JJ, Khan S, Jiang H, et al. Sirt5 is a NAD-dependent protein lysine demalonylase and desuccinylase. Science 2011;334:806-9.

[18] Feldman JL, Baeza J, Denu JM. Activation of the protein deacetylase SIRT6 by longchain fatty acids and widespread deacylation by mammalian sirtuins. J Biol Chem 2013;288:31350-6.

[19] Jiang H, Khan S, Wang Y, Charron G, He B, Sebastian C, et al. SIRT6 regulates TNFalpha secretion through hydrolysis of long-chain fatty acyl lysine. Nature 2013;496:110-3.

[20] Peng C, Lu Z, Xie Z, Cheng Z, Chen Y, Tan M, et al. The first identification of lysine malonylation substrates and its regulatory enzyme. Molecular \& cellular proteomics : MCP 2011;10:M111 012658.

[21] Tan M, Peng C, Anderson KA, Chhoy P, Xie Z, Dai L, et al. Lysine glutarylation is a protein posttranslational modification regulated by SIRT5. Cell Metab 2014;19:605-17.

[22] Ahuja N, Schwer B, Carobbio S, Waltregny D, North BJ, Castronovo V, et al. Regulation of insulin secretion by SIRT4, a mitochondrial ADP-ribosyltransferase. J Biol Chem 2007;282:33583-92.

[23] Frye RA. Characterization of five human cDNAs with homology to the yeast SIR2 gene: Sir2-like proteins (sirtuins) metabolize NAD and may have protein ADP-ribosyltransferase activity. Biochem Biophys Res Commun 1999;260:273-9.

[24] Haigis MC, Mostoslavsky R, Haigis KM, Fahie K, Christodoulou DC, Murphy AJ, et al. SIRT4 inhibits glutamate dehydrogenase and opposes the effects of calorie restriction in pancreatic beta cells. Cell 2006;126:941-54.

[25] Liszt G, Ford E, Kurtev M, Guarente L. Mouse Sir2 homolog SIRT6 is a nuclear ADPribosyltransferase. J Biol Chem 2005;280:21313-20. 
[26] Kumar S, Lombard DB. Mitochondrial sirtuins and their relationships with metabolic disease and cancer. Antioxidants \& redox signaling 2015;22:1060-77.

[27] Houtkooper RH, Canto C, Wanders RJ, Auwerx J. The secret life of NAD+: an old metabolite controlling new metabolic signaling pathways. Endocrine reviews 2010;31:194223.

[28] Herranz D, Munoz-Martin M, Canamero M, Mulero F, Martinez-Pastor B, FernandezCapetillo O, et al. Sirt1 improves healthy ageing and protects from metabolic syndromeassociated cancer. Nat Commun 2010;1:3.

[29] Someya S, Yu W, Hallows WC, Xu J, Vann JM, Leeuwenburgh C, et al. Sirt3 mediates reduction of oxidative damage and prevention of age-related hearing loss under caloric restriction. Cell 2010;143:802-12.

[30] Guarente L. Franklin H. Epstein Lecture: Sirtuins, aging, and medicine. N Engl J Med 2011;364:2235-44.

[31] Satoh A, Brace CS, Rensing N, Cliften P, Wozniak DF, Herzog ED, et al. Sirt1 extends life span and delays aging in mice through the regulation of Nk2 homeobox 1 in the DMH and LH. Cell Metab 2013;18:416-30.

[32] Kanfi Y, Naiman S, Amir G, Peshti V, Zinman G, Nahum L, et al. The sirtuin SIRT6 regulates lifespan in male mice. Nature 2012;483:218-21.

[33] Jemal A, Siegel R, Xu J, Ward E. Cancer statistics, 2010. CA: a cancer journal for clinicians 2010;60:277-300.

[34] Roth M, Chen WY. Sorting out functions of sirtuins in cancer. Oncogene 2014;33:160920. 
[35] Jeong SM, Xiao C, Finley LW, Lahusen T, Souza AL, Pierce K, et al. SIRT4 has tumorsuppressive activity and regulates the cellular metabolic response to DNA damage by inhibiting mitochondrial glutamine metabolism. Cancer Cell 2013;23:450-63.

[36] Csibi A, Fendt SM, Li C, Poulogiannis G, Choo AY, Chapski DJ, et al. The mTORC1 pathway stimulates glutamine metabolism and cell proliferation by repressing SIRT4. Cell 2013;153:840-54.

[37] Finley LW, Carracedo A, Lee J, Souza A, Egia A, Zhang J, et al. SIRT3 opposes reprogramming of cancer cell metabolism through HIF1alpha destabilization. Cancer Cell;19:416-28.

[38] Sebastian C, Zwaans BM, Silberman DM, Gymrek M, Goren A, Zhong L, et al. The histone deacetylase SIRT6 is a tumor suppressor that controls cancer metabolism. Cell 2012;151:1185-99.

[39] Guarente L. The many faces of sirtuins: Sirtuins and the Warburg effect. Nat Med 2014;20:24-5.

[40] Lombard DB, Alt FW, Cheng HL, Bunkenborg J, Streeper RS, Mostoslavsky R, et al. Mammalian Sir2 homolog SIRT3 regulates global mitochondrial lysine acetylation. Mol Cell Biol 2007;27:8807-14.

[41] Sol EM, Wagner SA, Weinert BT, Kumar A, Kim HS, Deng CX, et al. Proteomic investigations of lysine acetylation identify diverse substrates of mitochondrial deacetylase sirt3. PLoS One 2012;7:e50545.

[42] Rardin MJ, Newman JC, Held JM, Cusack MP, Sorensen DJ, Li B, et al. Label-free quantitative proteomics of the lysine acetylome in mitochondria identifies substrates of SIRT3 in metabolic pathways. Proc Natl Acad Sci U S A 2013;110:6601-6. 
[43] Hebert AS, Dittenhafer-Reed KE, Yu W, Bailey DJ, Selen ES, Boersma MD, et al. Calorie restriction and SIRT3 trigger global reprogramming of the mitochondrial protein acetylome. Mol Cell 2013;49:186-99.

[44] Bell EL, Emerling BM, Ricoult SJ, Guarente L. SirT3 suppresses hypoxia inducible factor 1alpha and tumor growth by inhibiting mitochondrial ROS production. Oncogene;30:2986-96.

[45] Kim HS, Patel K, Muldoon-Jacobs K, Bisht KS, Aykin-Burns N, Pennington JD, et al. SIRT3 is a mitochondria-localized tumor suppressor required for maintenance of mitochondrial integrity and metabolism during stress. Cancer Cell;17:41-52.

[46] Tao R, Coleman MC, Pennington JD, Ozden O, Park SH, Jiang H, et al. Sirt3-mediated deacetylation of evolutionarily conserved lysine 122 regulates MnSOD activity in response to stress. Mol Cell;40:893-904.

[47] Sundaresan NR, Samant SA, Pillai VB, Rajamohan SB, Gupta MP. SIRT3 is a stressresponsive deacetylase in cardiomyocytes that protects cells from stress-mediated cell death by deacetylation of Ku70. Mol Cell Biol 2008;28:6384-401.

[48] Ozden O, Park SH, Wagner BA, Yong Song H, Zhu Y, Vassilopoulos A, et al. SIRT3 deacetylates and increases pyruvate dehydrogenase activity in cancer cells. Free Radic Biol Med 2014;76:163-72.

[49] Fan J, Shan C, Kang HB, Elf S, Xie J, Tucker M, et al. Tyr phosphorylation of PDP1 toggles recruitment between ACAT1 and SIRT3 to regulate the pyruvate dehydrogenase complex. Mol Cell 2014;53:534-48. 
[50] Yang H, Zhou L, Shi Q, Zhao Y, Lin H, Zhang M, et al. SIRT3-dependent GOT2 acetylation status affects the malate-aspartate NADH shuttle activity and pancreatic tumor growth. EMBO J 2015;34:1110-25.

[51] Zhang CZ, Liu L, Cai M, Pan Y, Fu J, Cao Y, et al. Low SIRT3 expression correlates with poor differentiation and unfavorable prognosis in primary hepatocellular carcinoma. PLoS One 2012;7:e51703.

[52] Zhang YY, Zhou LM. Sirt3 inhibits hepatocellular carcinoma cell growth through reducing Mdm2-mediated p53 degradation. Biochem Biophys Res Commun 2012;423:26-31. [53] Ahn BH, Kim HS, Song S, Lee IH, Liu J, Vassilopoulos A, et al. A role for the mitochondrial deacetylase Sirt3 in regulating energy homeostasis. Proc Natl Acad Sci U S A 2008;105:14447-52.

[54] Cimen H, Han MJ, Yang Y, Tong Q, Koc H, Koc EC. Regulation of succinate dehydrogenase activity by SIRT3 in mammalian mitochondria. Biochemistry 2010;49:30411.

[55] Rahman M, Nirala NK, Singh A, Zhu LJ, Taguchi K, Bamba T, et al. Drosophila Sirt2/mammalian SIRT3 deacetylates ATP synthase beta and regulates complex V activity. J Cell Biol 2014;206:289-305.

[56] Hallows WC, Lee S, Denu JM. Sirtuins deacetylate and activate mammalian acetyl-CoA synthetases. Proc Natl Acad Sci U S A 2006;103:10230-5.

[57] Schwer B, Bunkenborg J, Verdin RO, Andersen JS, Verdin E. Reversible lysine acetylation controls the activity of the mitochondrial enzyme acetyl-CoA synthetase 2. Proc Natl Acad Sci U S A 2006. 
[58] Comerford SA, Huang Z, Du X, Wang Y, Cai L, Witkiewicz AK, et al. Acetate dependence of tumors. Cell 2014;159:1591-602.

[59] Mashimo T, Pichumani K, Vemireddy V, Hatanpaa KJ, Singh DK, Sirasanagandla S, et al. Acetate is a bioenergetic substrate for human glioblastoma and brain metastases. Cell 2014;159:1603-14.

[60] Schug ZT, Peck B, Jones DT, Zhang Q, Grosskurth S, Alam IS, et al. Acetyl-CoA synthetase 2 promotes acetate utilization and maintains cancer cell growth under metabolic stress. Cancer Cell 2015;27:57-71.

[61] Alhazzazi TY, Kamarajan P, Joo N, Huang JY, Verdin E, D'Silva NJ, et al. Sirtuin-3 (SIRT3), a novel potential therapeutic target for oral cancer. Cancer 2011;117:1670-8.

[62] Ashraf N, Zino S, Macintyre A, Kingsmore D, Payne AP, George WD, et al. Altered sirtuin expression is associated with node-positive breast cancer. Br J Cancer 2006;95:105661.

[63] Aury-Landas J, Bougeard G, Castel H, Hernandez-Vargas H, Drouet A, Latouche JB, et al. Germline copy number variation of genes involved in chromatin remodelling in families suggestive of Li-Fraumeni syndrome with brain tumours. European journal of human genetics : EJHG 2013;21:1369-76.

[64] Laurent G, German NJ, Saha AK, de Boer VC, Davies M, Koves TR, et al. SIRT4 coordinates the balance between lipid synthesis and catabolism by repressing malonyl CoA decarboxylase. Mol Cell 2013;50:686-98.

[65] Laurent G, de Boer VC, Finley LW, Sweeney M, Lu H, Schug TT, et al. SIRT4 represses peroxisome proliferator-activated receptor alpha activity to suppress hepatic fat oxidation. Mol Cell Biol 2013;33:4552-61. 
[66] Ho L, Titus AS, Banerjee KK, George S, Lin W, Deota S, et al. SIRT4 regulates ATP homeostasis and mediates a retrograde signaling via AMPK. Aging (Albany NY) 2013;5:835-49.

[67] Mathias RA, Greco TM, Oberstein A, Budayeva HG, Chakrabarti R, Rowland EA, et al. Sirtuin 4 is a lipoamidase regulating pyruvate dehydrogenase complex activity. Cell 2014;159:1615-25.

[68] Blaveri E, Simko JP, Korkola JE, Brewer JL, Baehner F, Mehta K, et al. Bladder cancer outcome and subtype classification by gene expression. Clin Cancer Res 2005;11:4044-55. [69] Garber ME, Troyanskaya OG, Schluens K, Petersen S, Thaesler Z, Pacyna-Gengelbach M, et al. Diversity of gene expression in adenocarcinoma of the lung. Proc Natl Acad Sci U S A 2001;98:13784-9.

[70] Wang Q, Wen YG, Li DP, Xia J, Zhou CZ, Yan DW, et al. Upregulated INHBA expression is associated with poor survival in gastric cancer. Medical oncology 2012;29:7783.

[71] Jeong SM, Lee A, Lee J, Haigis MC. SIRT4 protein suppresses tumor formation in genetic models of Myc-induced B cell lymphoma. J Biol Chem 2014;289:4135-44.

[72] Metallo CM, Gameiro PA, Bell EL, Mattaini KR, Yang J, Hiller K, et al. Reductive glutamine metabolism by IDH1 mediates lipogenesis under hypoxia. Nature 2012;481:380-4.

[73] Mullen AR, Wheaton WW, Jin ES, Chen PH, Sullivan LB, Cheng T, et al. Reductive carboxylation supports growth in tumour cells with defective mitochondria. Nature 2012;481:385-8. 
[74] Wise DR, DeBerardinis RJ, Mancuso A, Sayed N, Zhang XY, Pfeiffer HK, et al. Myc regulates a transcriptional program that stimulates mitochondrial glutaminolysis and leads to glutamine addiction. Proc Natl Acad Sci U S A 2008;105:18782-7.

[75] Gao P, Tchernyshyov I, Chang TC, Lee YS, Kita K, Ochi T, et al. c-Myc suppression of miR-23a/b enhances mitochondrial glutaminase expression and glutamine metabolism. Nature 2009;458:762-5.

[76] Choo AY, Kim SG, Vander Heiden MG, Mahoney SJ, Vu H, Yoon SO, et al. Glucose addiction of TSC null cells is caused by failed mTORC1-dependent balancing of metabolic demand with supply. Mol Cell 2010;38:487-99.

[77] Wang L, Zhou H, Wang Y, Cui G, Di LJ. CtBP maintains cancer cell growth and metabolic homeostasis via regulating SIRT4. Cell death \& disease 2015;6:e1620.

[78] Frye RA. Phylogenetic classification of prokaryotic and eukaryotic Sir2-like proteins. Biochem Biophys Res Commun 2000;273:793-8.

[79] Park J, Chen Y, Tishkoff DX, Peng C, Tan M, Dai L, et al. SIRT5-mediated lysine desuccinylation impacts diverse metabolic pathways. Mol Cell 2013;50:919-30.

[80] Nakagawa T, Lomb DJ, Haigis MC, Guarente L. SIRT5 Deacetylates carbamoyl phosphate synthetase 1 and regulates the urea cycle. Cell 2009;137:560-70.

[81] Ogura M, Nakamura Y, Tanaka D, Zhuang X, Fujita Y, Obara A, et al. Overexpression of SIRT5 confirms its involvement in deacetylation and activation of carbamoyl phosphate synthetase 1. Biochem Biophys Res Commun 2010;393:73-8.

[82] Polletta L, Vernucci E, Carnevale I, Arcangeli T, Rotili D, Palmerio S, et al. SIRT5 regulation of ammonia-induced autophagy and mitophagy. Autophagy 2015;11:253-70. 
[83] Lin ZF, Xu HB, Wang JY, Lin Q, Ruan Z, Liu FB, et al. SIRT5 desuccinylates and activates SOD1 to eliminate ROS. Biochem Biophys Res Commun 2013;441:191-5.

[84] Papa L, Hahn M, Marsh EL, Evans BS, Germain D. SOD2 to SOD1 switch in breast cancer. J Biol Chem 2014;289:5412-6.

[85] Somwar R, Erdjument-Bromage H, Larsson E, Shum D, Lockwood WW, Yang G, et al. Superoxide dismutase 1 (SOD1) is a target for a small molecule identified in a screen for inhibitors of the growth of lung adenocarcinoma cell lines. Proc Natl Acad Sci U S A 2011;108:16375-80.

[86] Glasauer A, Sena LA, Diebold LP, Mazar AP, Chandel NS. Targeting SOD1 reduces experimental non-small-cell lung cancer. J Clin Invest 2014;124:117-28.

[87] Baysal BE, Ferrell RE, Willett-Brozick JE, Lawrence EC, Myssiorek D, Bosch A, et al. Mutations in SDHD, a mitochondrial complex II gene, in hereditary paraganglioma. Science 2000;287:848-51.

[88] Cancer Genome Atlas Research N. Integrated genomic analyses of ovarian carcinoma. Nature 2011;474:609-15.

[89] Lu W, Zuo Y, Feng Y, Zhang M. SIRT5 facilitates cancer cell growth and drug resistance in non-small cell lung cancer. Tumour biology : the journal of the International Society for Oncodevelopmental Biology and Medicine 2014;35:10699-705.

[90] Michishita E, McCord RA, Berber E, Kioi M, Padilla-Nash H, Damian M, et al. SIRT6 is a histone $\mathrm{H} 3$ lysine 9 deacetylase that modulates telomeric chromatin. Nature 2008;452:492-6. 
[91] Michishita E, McCord RA, Boxer LD, Barber MF, Hong T, Gozani O, et al. Cell cycledependent deacetylation of telomeric histone H3 lysine K56 by human SIRT6. Cell Cycle 2009;8:2664-6.

[92] Yang B, Zwaans BM, Eckersdorff M, Lombard DB. The sirtuin SIRT6 deacetylates H3 K56Ac in vivo to promote genomic stability. Cell Cycle 2009;8:2662-3.

[93] Gil R, Barth S, Kanfi Y, Cohen HY. SIRT6 exhibits nucleosome-dependent deacetylase activity. Nucleic Acids Res 2013;41:8537-45.

[94] Mao Z, Hine C, Tian X, Van Meter M, Au M, Vaidya A, et al. SIRT6 promotes DNA repair under stress by activating PARP1. Science;332:1443-6.

[95] Van Meter M, Kashyap M, Rezazadeh S, Geneva AJ, Morello TD, Seluanov A, et al. SIRT6 represses LINE1 retrotransposons by ribosylating KAP1 but this repression fails with stress and age. Nat Commun 2014;5:5011.

[96] Mostoslavsky R, Chua KF, Lombard DB, Pang WW, Fischer MR, Gellon L, et al. Genomic instability and aging-like phenotype in the absence of mammalian SIRT6. Cell 2006;124:315-29.

[97] Kaidi A, Weinert BT, Choudhary C, Jackson SP. Human SIRT6 promotes DNA end resection through CtIP deacetylation. Science;329:1348-53.

[98] McCord RA, Michishita E, Hong T, Berber E, Boxer LD, Kusumoto R, et al. SIRT6 stabilizes DNA-dependent protein kinase at chromatin for DNA double-strand break repair. Aging (Albany NY) 2009;1:109-21.

[99] Toiber D, Erdel F, Bouazoune K, Silberman DM, Zhong L, Mulligan P, et al. SIRT6 recruits SNF2H to DNA break sites, preventing genomic instability through chromatin remodeling. Mol Cell 2013;51:454-68. 
[100] Kim HS, Xiao C, Wang RH, Lahusen T, Xu X, Vassilopoulos A, et al. Hepatic-specific disruption of SIRT6 in mice results in fatty liver formation due to enhanced glycolysis and triglyceride synthesis. Cell Metab 2010;12:224-36.

[101] Xiong X, Tao R, DePinho RA, Dong XC. Deletion of hepatic FoxO1/3/4 genes in mice significantly impacts on glucose metabolism through downregulation of gluconeogenesis and upregulation of glycolysis. PLoS One 2013;8:e74340.

[102] Zhong L, D'Urso A, Toiber D, Sebastian C, Henry RE, Vadysirisack DD, et al. The histone deacetylase Sirt6 regulates glucose homeostasis via Hif1alpha. Cell 2010;140:28093.

[103] Kugel S, Mostoslavsky R. Chromatin and beyond: the multitasking roles for SIRT6. Trends Biochem Sci 2014;39:72-81.

[104] Dominy JE, Jr., Lee Y, Jedrychowski MP, Chim H, Jurczak MJ, Camporez JP, et al. The deacetylase Sirt6 activates the acetyltransferase GCN5 and suppresses hepatic gluconeogenesis. Mol Cell 2012;48:900-13.

[105] Lyssiotis CA, Cantley LC. SIRT6 puts cancer metabolism in the driver's seat. Cell 2012;151:1155-6.

[106] Lai CC, Lin PM, Lin SF, Hsu CH, Lin HC, Hu ML, et al. Altered expression of SIRT gene family in head and neck squamous cell carcinoma. Tumour biology : the journal of the International Society for Oncodevelopmental Biology and Medicine 2013;34:1847-54.

[107] Marquardt JU, Fischer K, Baus K, Kashyap A, Ma S, Krupp M, et al. Sirtuin-6dependent genetic and epigenetic alterations are associated with poor clinical outcome in hepatocellular carcinoma patients. Hepatology 2013;58:1054-64. 
[108] Min L, Ji Y, Bakiri L, Qiu Z, Cen J, Chen X, et al. Liver cancer initiation is controlled by AP-1 through SIRT6-dependent inhibition of survivin. Nat Cell Biol 2012;14:1203-11. [109] Lin Z, Yang H, Tan C, Li J, Liu Z, Quan Q, et al. USP10 antagonizes c-Myc transcriptional activation through SIRT6 stabilization to suppress tumor formation. Cell reports 2013;5:1639-49.

[110] Kim EJ, Juhnn YS. Cyclic AMP Signaling Reduces Sirtuin 6 Expression in Non-small Cell Lung Cancer Cells by Promoting Ubiquitin-Proteasomal Degradation via Inhibition of the Raf-MEK-ERK (Raf/Mitogen-activated Extracellular Signal-regulated Kinase/Extracellular Signal-regulated Kinase) Pathway. J Biol Chem 2015;290:9604-13.

[111] Choe M, Brusgard JL, Chumsri S, Bhandary L, Zhao XF, Lu S, et al. The RUNX2 Transcription Factor Negatively Regulates SIRT6 Expression to Alter Glucose Metabolism in Breast Cancer Cells. J Cell Biochem 2015.

[112] Wu M, Seto E, Zhang J. E2F1 enhances glycolysis through suppressing Sirt6 transcription in cancer cells. Oncotarget 2015.

[113] Bauer I, Grozio A, Lasiglie D, Basile G, Sturla L, Magnone M, et al. The NAD+dependent histone deacetylase SIRT6 promotes cytokine production and migration in pancreatic cancer cells by regulating Ca2+ responses. J Biol Chem 2012;287:40924-37.

[114] Khongkow M, Olmos Y, Gong C, Gomes AR, Monteiro LJ, Yague E, et al. SIRT6 modulates paclitaxel and epirubicin resistance and survival in breast cancer. Carcinogenesis 2013;34:1476-86.

[115] Liu Y, Xie QR, Wang B, Shao J, Zhang T, Liu T, et al. Inhibition of SIRT6 in prostate cancer reduces cell viability and increases sensitivity to chemotherapeutics. Protein \& cell 2013. 
[116] Martinez-Pastor B, Mostoslavsky R. Sirtuins, metabolism, and cancer. Front Pharmacol;3:22.

[117] Dioum EM, Chen R, Alexander MS, Zhang Q, Hogg RT, Gerard RD, et al. Regulation of hypoxia-inducible factor 2alpha signaling by the stress-responsive deacetylase sirtuin 1 . Science 2009;324:1289-93.

[118] Lim JH, Lee YM, Chun YS, Chen J, Kim JE, Park JW. Sirtuin 1 modulates cellular responses to hypoxia by deacetylating hypoxia-inducible factor 1alpha. Mol Cell 2010;38:864-78.

[119] Laemmle A, Lechleiter A, Roh V, Schwarz C, Portmann S, Furer C, et al. Inhibition of SIRT1 impairs the accumulation and transcriptional activity of HIF-1alpha protein under hypoxic conditions. PLoS One 2012;7:e33433.

[120] Liu G, Bi Y, Shen B, Yang H, Zhang Y, Wang X, et al. SIRT1 limits the function and fate of myeloid-derived suppressor cells in tumors by orchestrating HIF-1alpha-dependent glycolysis. Cancer Res 2014;74:727-37.

[121] Yoon H, Shin SH, Shin DH, Chun YS, Park JW. Differential roles of Sirt1 in HIF1alpha and HIF-2alpha mediated hypoxic responses. Biochem Biophys Res Commun 2014;444:36-43.

[122] Mao B, Zhao G, Lv X, Chen HZ, Xue Z, Yang B, et al. Sirt1 deacetylates c-Myc and promotes c-Myc/Max association. The international journal of biochemistry \& cell biology 2011;43:1573-81.

[123] Yuan J, Minter-Dykhouse K, Lou Z. A c-Myc-SIRT1 feedback loop regulates cell growth and transformation. J Cell Biol 2009;185:203-11. 
[124] Menssen A, Hydbring P, Kapelle K, Vervoorts J, Diebold J, Luscher B, et al. The cMYC oncoprotein, the NAMPT enzyme, the SIRT1-inhibitor DBC1, and the SIRT1 deacetylase form a positive feedback loop. Proc Natl Acad Sci U S A 2012;109:E187-96.

[125] Marshall GM, Liu PY, Gherardi S, Scarlett CJ, Bedalov A, Xu N, et al. SIRT1 promotes N-Myc oncogenesis through a positive feedback loop involving the effects of MKP3 and ERK on N-Myc protein stability. PLoS Genet 2011;7:e1002135.

[126] Vettraino M, Manerba M, Govoni M, Di Stefano G. Galloflavin suppresses lactate dehydrogenase activity and causes MYC downregulation in Burkitt lymphoma cells through NAD/NADH-dependent inhibition of sirtuin-1. Anti-cancer drugs 2013;24:862-70.

[127] Lan F, Cacicedo JM, Ruderman N, Ido Y. SIRT1 modulation of the acetylation status, cytosolic localization, and activity of LKB1. Possible role in AMP-activated protein kinase activation. J Biol Chem 2008;283:27628-35.

[128] Hardie DG. AMP-activated protein kinase: a cellular energy sensor with a key role in metabolic disorders and in cancer. Biochemical Society transactions 2011;39:1-13. [129] Sanders MJ, Grondin PO, Hegarty BD, Snowden MA, Carling D. Investigating the mechanism for AMP activation of the AMP-activated protein kinase cascade. Biochem $\mathbf{J}$ 2007;403:139-48.

[130] Faubert B, Boily G, Izreig S, Griss T, Samborska B, Dong Z, et al. AMPK is a negative regulator of the Warburg effect and suppresses tumor growth in vivo. Cell Metab $2013 ; 17: 113-24$.

[131] Kim HS, Vassilopoulos A, Wang RH, Lahusen T, Xiao Z, Xu X, et al. SIRT2 maintains genome integrity and suppresses tumorigenesis through regulating APC/C activity. Cancer Cell;20:487-99. 
[132] Serrano L, Martinez-Redondo P, Marazuela-Duque A, Vazquez BN, Dooley SJ, Voigt $\mathrm{P}$, et al. The tumor suppressor SirT2 regulates cell cycle progression and genome stability by modulating the mitotic deposition of H4K20 methylation. Genes Dev 2013;27:639-53.

[133] Almeida A, Bolanos JP, Moncada S. E3 ubiquitin ligase APC/C-Cdh1 accounts for the Warburg effect by linking glycolysis to cell proliferation. Proc Natl Acad Sci U S A 2010;107:738-41.

[134] Seo KS, Park JH, Heo JY, Jing K, Han J, Min KN, et al. SIRT2 regulates tumour hypoxia response by promoting HIF-1alpha hydroxylation. Oncogene 2015;34:1354-62.

[135] Hitosugi T, Zhou L, Elf S, Fan J, Kang HB, Seo JH, et al. Phosphoglycerate mutase 1 coordinates glycolysis and biosynthesis to promote tumor growth. Cancer Cell 2012;22:585600.

[136] Xu Y, Li F, Lv L, Li T, Zhou X, Deng CX, et al. Oxidative stress activates SIRT2 to deacetylate and stimulate phosphoglycerate mutase. Cancer Res 2014;74:3630-42.

[137] Wang YP, Zhou LS, Zhao YZ, Wang SW, Chen LL, Liu LX, et al. Regulation of G6PD acetylation by SIRT2 and KAT9 modulates NADPH homeostasis and cell survival during oxidative stress. EMBO J 2014;33:1304-20.

[138] Liu PY, Xu N, Malyukova A, Scarlett CJ, Sun YT, Zhang XD, et al. The histone deacetylase SIRT2 stabilizes Myc oncoproteins. Cell Death Differ 2013;20:503-14.

[139] Barber MF, Michishita-Kioi E, Xi Y, Tasselli L, Kioi M, Moqtaderi Z, et al. SIRT7 links H3K18 deacetylation to maintenance of oncogenic transformation. Nature 2012;487:114-8.

[140] Kim W, Kim JE. SIRT7 an emerging sirtuin: deciphering newer roles. J Physiol Pharmacol 2013;64:531-4. 
[141] Zhang S, Chen P, Huang Z, Hu X, Chen M, Hu S, et al. Sirt7 promotes gastric cancer growth and inhibits apoptosis by epigenetically inhibiting miR-34a. Scientific reports 2015;5:9787.

[142] Yu H, Ye W, Wu J, Meng X, Liu RY, Ying X, et al. Overexpression of sirt7 exhibits oncogenic property and serves as a prognostic factor in colorectal cancer. Clin Cancer Res 2014;20:3434-45.

[143] Hubbi ME, Hu H, Kshitiz, Gilkes DM, Semenza GL. Sirtuin-7 inhibits the activity of hypoxia-inducible factors. J Biol Chem 2013;288:20768-75.

[144] Shin J, He M, Liu Y, Paredes S, Villanova L, Brown K, et al. SIRT7 represses Myc activity to suppress ER stress and prevent fatty liver disease. Cell reports 2013;5:654-65.

[145] Grey ADNJd. Life Span Extension Research and Public Debate: Social Considerations. Studies in Ethics, Law and Technology 2007;1, Article 5.

[146] Ben-Shmuel S, Rostoker R, Scheinman EJ, LeRoith D. Metabolic Syndrome, Type 2 Diabetes, and Cancer: Epidemiology and Potential Mechanisms. Handbook of experimental pharmacology 2015.

[147] Ligibel J. Lifestyle factors in cancer survivorship. J Clin Oncol 2012;30:3697-704.

[148] Trounce I, Byrne E, Marzuki S. Decline in skeletal muscle mitochondrial respiratory chain function: possible factor in ageing. Lancet 1989;1:637-9.

[149] Ross JM, Oberg J, Brene S, Coppotelli G, Terzioglu M, Pernold K, et al. High brain lactate is a hallmark of aging and caused by a shift in the lactate dehydrogenase A/B ratio. Proc Natl Acad Sci U S A 2010;107:20087-92. 
[150] El-Hassan A, Zubairu S, Hothersall JS, Greenbaum AL. Age-related changes in enzymes of rat brain. 1. Enzymes of glycolysis, the pentose phosphate pathway and lipogenesis. Enzyme 1981;26:107-12.

[151] Hagopian K, Ramsey JJ, Weindruch R. Influence of age and caloric restriction on liver glycolytic enzyme activities and metabolite concentrations in mice. Experimental gerontology 2003;38:253-66.

[152] Zhou Q, Lam PY, Han D, Cadenas E. Activation of c-Jun-N-terminal kinase and decline of mitochondrial pyruvate dehydrogenase activity during brain aging. FEBS Lett 2009;583:1132-40.

[153] Salminen A, Kaarniranta K. Glycolysis links p53 function with NF-kappaB signaling: impact on cancer and aging process. Journal of cellular physiology 2010;224:1-6.

[154] Yoshino J, Mills KF, Yoon MJ, Imai S. Nicotinamide mononucleotide, a key NAD(+) intermediate, treats the pathophysiology of diet- and age-induced diabetes in mice. Cell Metab 2011;14:528-36.

[155] Cohen HY, Miller C, Bitterman KJ, Wall NR, Hekking B, Kessler B, et al. Calorie restriction promotes mammalian cell survival by inducing the SIRT1 deacetylase. Science 2004;305:390-2.

[156] Canto C, Auwerx J. Caloric restriction, SIRT1 and longevity. Trends Endocrinol Metab 2009;20:325-31.

[157] Gomes AP, Price NL, Ling AJ, Moslehi JJ, Montgomery MK, Rajman L, et al. Declining $\mathrm{NAD}(+)$ induces a pseudohypoxic state disrupting nuclear-mitochondrial communication during aging. Cell 2013;155:1624-38. 
[158] Lanza IR, Nair KS. Mitochondrial function as a determinant of life span. Pflugers Archiv : European journal of physiology 2010;459:277-89.

[159] Lombard DB, Miller RA. Ageing: Sorting out the sirtuins. Nature 2012;483:166-7.

\section{Figure Legends}

Figure 1. Biological and metabolic functions of the different mammalian sirtuins. Dashed lines indicate known biological targets where their involvement in cancer remains to be established. 


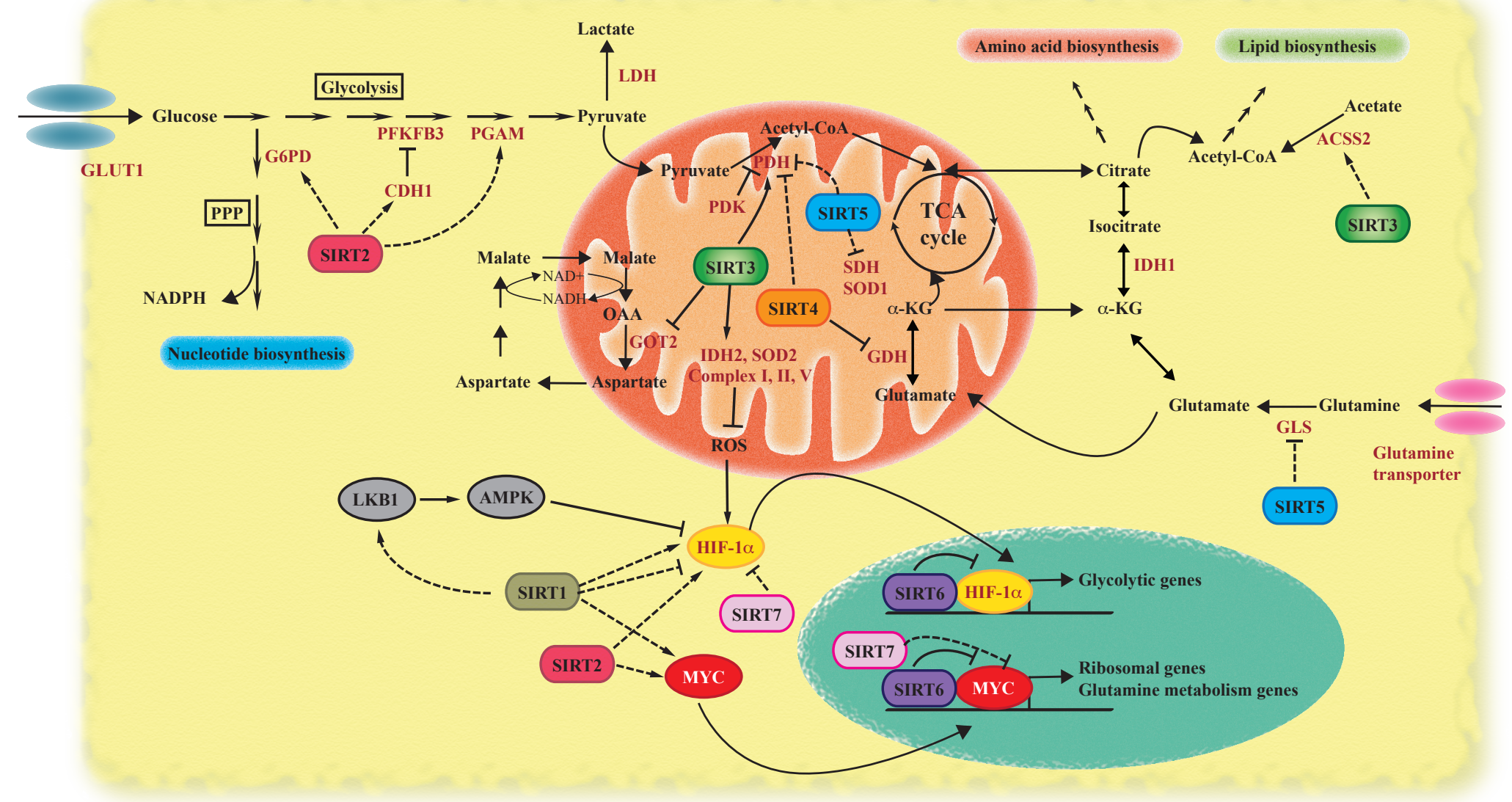


Table 1. Biochemical properties of mammalian sirtuins relevant in cancer metabolism.

\begin{tabular}{|c|c|c|c|c|}
\hline Sirtuin & Cellular localization & Biochemical activity & Targets & Metabolic pathway \\
\hline \multirow[t]{3}{*}{ SIRT1 } & Cytoplasm & Deacetylase & HIF- $1 \alpha /$ HIF- $2 \alpha$ & Unknown \\
\hline & & & MYC & Glycolysis ( $L D H a$ expression) \\
\hline & Nucleus & Deacetylase & Unknown & Unknown \\
\hline \multirow[t]{4}{*}{ SIRT2 } & Cytoplasm & Deacetylase & HIF-1 $\alpha / \mathrm{CDH} 1 / \mathrm{PGAM}$ & Glycolysis \\
\hline & & & G6PD & Pentose Phospate Pathway \\
\hline & & & MYC & Unknown \\
\hline & Nucleus & Deacetylase & Unknown & Unknown \\
\hline \multirow[t]{5}{*}{ SIRT3 } & Mitochondria & Deacetylase & SOD2/IDH2/FOXO3a & Glycolysis \\
\hline & & & PDH-E1 $\alpha$ & Glycolysis \\
\hline & & & GOT2 & Mal-Asp NADH shuttle \\
\hline & & & Complex I, II, V & Unknown \\
\hline & Cytoplasm & Deacetylase & ACSS2 & Unknown \\
\hline \multirow[t]{2}{*}{ SIRT4 } & Mitochondria & ADP-ribosylase & GDH & Glutamine metabolism \\
\hline & & Lipoamidase & $\mathrm{PDH}$ & Unknown \\
\hline \multirow{2}{*}{ SIRT5 } & Mitochondria & Desuccinylase & GLS & Unknown \\
\hline & & & $\mathrm{PDH} / \mathrm{SDH} / \mathrm{SOD} 1$ & Unknown \\
\hline \multirow[t]{3}{*}{ SIRT6 } & Nucleus & Deacetylase & H3К9ac & Glycolysis \\
\hline & & & H3К $56 \mathrm{ac}$ & Glutamine metabolism \\
\hline & & & & Ribosome biogenesis \\
\hline \multirow[t]{2}{*}{ SIRT7 } & Nucleus & Deacetylase & $\mathrm{H} 3 \mathrm{~K} 18 \mathrm{ac}$ & Unknown \\
\hline & Cytoplasm & Deacetylase & HIF- $1 \alpha /$ HIF- $2 \alpha$ & Unknown \\
\hline
\end{tabular}

